\title{
Racismo não dá conta: antinegritude, a dinâmica ontológica e social definidora da modernidade
}

\author{
Racism does not suffice: anti-blackness, the defining social and \\ ontological dynamic of modernity
}

João H. Costa Vargas*

\begin{abstract}
Resumo - Este artigo propõe que a categoria analítica "racismo" não é adequada para analisar as experiências de pessoas negras, seja no Brasil, seja no restante da diáspora. Por supor que experiências negras e experiências não negras são análogas e, portanto, comensuráveis, o racismo não dá conta da singularidade das experiências negras. De fato, as pessoas negras ocupam uma posição única na constituição das subjetividades modernas. Constituindo as identidades em oposição às quais a Humanidade se define, a pessoa negra é simultaneamente excluída da família humana e absolutamente necessária à constituição dessa mesma família. A antinegritude, ao contrário do racismo, aceita essa proposição como ponto de partida e sugere que a díade fundamental do mundo moderno é "pessoas negras/pessoas não negras". Essa díade sugere um mundo social planetário muito diferente daquele do racimo. De acordo com o racismo, a díade definidora do mundo social planetário é "pessoas brancas/pessoas não brancas".
\end{abstract}

Palavras-chave: racismo; negritude; antinegritude.

\begin{abstract}
This article proposes that the analytical category "racism" is not adequate to analyze the experiences of black people, either in Brazil or in the rest of the diaspora. By supposing that black experiences and non-black experiences are analogous and therefore commensurable, racism does not account for the uniqueness of black experiences. Indeed, black people occupy a unique position in the constitution of modern subjectivities. Constituting the opposing identities, in which humanity defines itself, the black person is simultaneously excluded from the human family and indispensable for the constitution of that same family. Antiblackness, unlike racism, accepts this proposition as a starting point and suggests that the fundamental dyad of the modern world is "black people/ non-black people." This dyad suggests a planetary social world very different from that of racism. According to racism, the defining dyad of the planetary social world is "white people/non-white people."

Keywords: racism; blackness; anti-blackness.
\end{abstract}

\footnotetext{
* Professor de Antropologia na Universidade da Califórnia. Suas publicações incluem Catching Hell in the City of Angels (2006), Never Meant to Survive (2008), State of White Supremacy, coeditado por Moon-Kie Jung e Eduardo Bonilla-Silva (2011) e The Denial of Antiblackness: Multiracial Redemption and Black Suffering (2018). Seus trabalhos baseiam-se em projetos colaborativos no Rio de Janeiro, São Paulo e Salvador (no Brasil), como também em Austin e Los Angeles (nos Estados Unidos). E-mail: joao.vargas@ucr.edu. ORCID: https://orcid.org/ 0000-0002-1335-0179.
} 


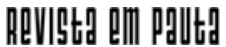

\} RACISMO NÃO DÁ CONTA - VARGAS, J. H. C. \}

DOI: $10.12957 /$ REP.2020.47201

O racismo deriva de uma díade que separa o mundo social em dois grupos: pessoas brancas de um lado e pessoas não brancas de outro. Esse esquema sugere que as formas de desigualdade a que pessoas não brancas estão sujeitas são resultado da supremacia branca, a qual valoriza a branquitude ao mesmo tempo em que desvaloriza a não branquitude. ${ }^{1}$

O foco na supremacia branca permite uma compreensão de desigualdades sociais cujas dinâmicas derivam da construção social da raça, articuladas às construções sociais do gênero e da sexualidade. Portanto, raça, gênero, sexualidade e classe social, entre outras variáveis, são fundamentais nas análises críticas visando o entendimento e o fim da opressão. A opressão, da perspectiva que se tornou canônica, pelo menos nos meios progressistas, é entendida como o resultado da combinação de opressões múltiplas. O manifesto de 1977 das mulheres negras, das classes trabalhadoras e majoritariamente queer do Combahee River Collective expressa, de maneira exemplar, essa perspectiva crítica da supremacia branca, enfatizando uma análise interseccional. ${ }^{2}$ Diz o manifesto:

No momento presente, a proposição mais geral de nossa política é que nós estamos comprometidas ativamente à luta contra as opressões de raça, sexo, heterossexualidade, e classe, e temos como nosso objetivo principal o desenvolvimento de uma análise e prática integradas que se baseiam no fato de que os principais sistemas de opressão são interconectados. A síntese dessas opressões cria as condições de nossas vidas. Enquanto mulheres negras, consideramos o feminismo negro o movimento político lógico no combate às opressões múltiplas e simultâneas que todas mulheres de cor vivenciam. (tradução livre). ${ }^{3}$

É inegável o poder que essa perspectiva analítica tem de aglutinar grupos sociais oprimidos díspares. Ao tornar as condições das vidas de mulheres negras comensuráveis às das mulheres não brancas, ou de cor (asiáticas, latinas, indígenas e outras), o manifesto abre a possibilidade da formação de blocos políticos multirraciais, que lutam contra as formas articuladas de opressão. Esses blocos políticos têm como base analítica e ética o reconhecimento de que tais opressões são o resultado da supremacia branca global. As opressões que cada grupo sofre não são necessariamente as

\footnotetext{
${ }^{1}$ Pessoas não negras podem investir na branquitude e pessoas brancas podem desinvestir-se da branquitude e dos benefícios que dela decorrem. Algumas das consequências dessas proposições são que pessoas negras, não raro, podem ser apoiadoras da supremacia branca, e que nem todas as pessoas brancas são apoiadoras da supremacia branca (apesar de ser extremamente difícil não se beneficiar dela). Para uma análise mais detalhada, ver: George Lipsitz (1998).

${ }^{2}$ Essa análise mais tarde ganha outra abordagem, mais literal (no sentido de utilizar a imagem do cruzamento de trânsito - intersection, em inglês - para pensar nas formas de opressão diversas e que se combinam) no trabalho (CRENSHAW, 1991).

3 "The most general statement of our politics at the present time would be that we are actively committed to struggling against racial, sexual, heterosexual, and class oppression, and see as our particular task the development of integrated analysis and practice based upon the fact that the major systems of oppression are interlocking. The synthesis of these oppressions creates the conditions of our lives. As Black women we see Black feminism as the logical political movement to combat the manifold and simultaneous oppressions that all women of color face." (COMBAHEE, 1977, p.1).
} 


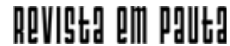

\} RACISMO NÃO DÁ CONTA - VARGAS, J. H. C. \}

DOI: $10.12957 /$ REP.2020.47201

mesmas, mas elas são comparáveis e traduzíveis umas às outras porque provêm de uma mesma fonte, qual seja, a supremacia branca cis-heteronormativa patriarcal e capitalista. E da comparação e reconhecimento das várias opressões sofridas por grupos não brancos diversamente categorizados (simultaneamente pela classe social, raça, gênero, sexualidade, entre outras variáveis) resultam denominadores comuns, os quais ressaltam experiências compartilhadas.

Perspectivas analíticas e políticas mais recentes, que reconhecem a singularidade e mesmo a incomensurabilidade da condição negra, sugerem uma abordagem alternativa. Propondo que a díade definidora do mundo social é entre pessoas negras, de um lado, e pessoas não negras, de outro (ao invés de brancas e não brancas, como sugere a abordagem da supremacia branca). Tais perspectivas emergem de análises demográficas e de economia política (MELVIN; SHAPIRO, 1995; YANCEY, 2004; OLIVEIRA, 2007), bem como de esforços teóricos que apresentam conceitos tais como o de morte social e da vida póstuma da escravidão (JAMES, 1999; HARTMAN, 1997; WILDERSON, 2010).

De acordo com essas análises e esforços teóricos, as pessoas negras vis-à-vis às não negras são (a) sistemática e singularmente excluídas (de moradia digna, emprego, saúde, segurança, vida) e (b) constituem o não ser que fundamenta as subjetividades não negras do mundo moderno. Ambas as proposições indicam uma lógica que resulta na negação tanto ontológica quanto social da pessoa negra. Tal lógica é a antinegritude. No restante desse ensaio, ofereço alguns parâmetros que definem a antinegritude.

Como ponto de partida, a antinegritude é o fundamento da Humanidade. O ser moderno se define em oposição ao não ser negro. Quando Frantz Fanon (1967) descreve o inconsciente coletivo moderno, ele coloca o medo e o ódio à pessoa negra no seu centro nevrálgico. O ódio à pessoa negra na verdade é o ódio ao não ser, ao não lugar, ao não Humano (FANON, 1967; GORDON, 1999). Assim, ao passo que, da perspectiva do racismo, a discriminação racial é algo que pode ser eliminado ou pelo menos combatido, da perspectiva da antinegritude, essa proposição fica mais complicada. Isso porque, nessa perspectiva, trata-se não apenas de eliminar um conjunto de práticas sociais e institucionais (o racismo), mas de questionar fundamentalmente a própria noção de Humanidade e sua dependência na exclusão daquelas consideradas não pessoas. A antinegritude é constitutiva da Humanidade. Ser humano é não ser negro. Tendo isso em vista, como elaborar políticas públicas, práticas sociais ou noções de ser que questionam o conceito de Humanidade?

Podemos pensar o racismo (como por exemplo o racismo antinegro, que não é o mesmo que a antinegritude, como explico abaixo) como valores, sentimentos e efeitos sociais que, juntamente com práticas cotidianas e institucionais (que por sua vez impactam valores e sentimentos, numa relação de retroalimentação constante), produzem desvantagens estruturais, 


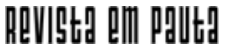

\} RACISMO NÃO DÁ CONTA - VARGAS, J. H. C. \}

DOI: $10.12957 /$ REP.2020.47201

ubíquas, trans-históricas e contemporâneas para pessoas negras. Na medida em que muitas dessas desvantagens estão vinculadas à distribuição de recursos sociais finitos, elas vinculam-se também a vantagens para pessoas não negras.

É necessário frisar que tais valores, sentimentos e efeitos sociais, que podem ser medidos através de vários métodos de análise (demográficos, sociológicos, etnográficos), constituem apenas uma tradução imperfeita de um princípio fundante. O princípio fundante é a antinegritude. As desvantagens que recaem sobre as pessoas negras estão associadas à negação da humanidade da pessoa negra - à negação ontológica da pessoa negra. A existência ontológica normativa, a existência não negra, só é possível enquanto oposto da não existência, a não existência da pessoa negra. A não existência é a pessoa negra, a negritude. Esse é o princípio fundamental da constituição da pessoa moderna.

A não negritude equivale à naturalização da presença, que por sua vez se traduz, sempre imperfeitamente, em graus de cidadania. Tais graus de cidadania são fundamental e permanentemente negados às pessoas negras. Digo graus de cidadania porque cada grupo não negro, definido pela intersecção de vários fatores, como classe social, raça, gênero e sexualidade, ocupará uma posição de privilégios e desvantagens. Essa posição se atualiza não com relação à branquitude normativa, como querem as análises do racismo e da supremacia branca, mas com relação à negritude fundamental. Ou seja, normativamente, o maior desafio social é distanciar-se ao máximo da negritude (e não, como querem as perspectivas progressistas mais comuns, as que se baseiam no conceito da supremacia branca, aproximar-se da branquitude) (YANCEY, 2004). Por cidadania entendo não somente a sua definição jurídica e política, mas algo mais amplo: o pertencimento à família humana. A não pessoa negra é, por princípio fundante, não humana; a não pessoa, em sua ausência (sempre presente), que torna possível a presença naturalizada das pessoas não negras (FANON, 1967).

Essa escala ontológica, ao mesmo tempo em que exclui as pessoas negras, comporta graus e variações de Humanidade. A díade pessoas negras/ pessoas não negras nos permite entender como homens brancos cis-heteronormativos de classes sociais privilegiadas constituem uma das posicionalidades extremas de privilégio, ao mesmo tempo em que pessoas não negras de variadas raças, gêneros, sexualidades e classes sociais podem ser localizadas no mesmo contínuo de Humanidade, apesar de sofrerem vários tipos de opressão. $O$ aspecto crítico dessa escala é que ela se define pela ausência - pela expulsão - fundamental das pessoas negras. Apesar de não fazerem parte da escala de Humanidade, as (não) pessoas negras definem essa escala precisamente porque são o seu contraste de base. O requerimento cardeal de pertencimento à Humanidade é que a pessoa não seja negra.

Tal escala de humanidade estrutura um campo de posicionalidades. Todas as posicionalidades ontológicas nesse campo se definem com relação à não pessoa negra. A não pessoa negra é sempre a referência, mas, como 


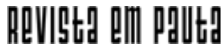

\} RACISMO NÃO DÁ CONTA - VARGAS, J. H. C. \}

DOI: $10.12957 /$ REP.2020.47201

insiste Frantz Fanon (1967), ela mesma não tem peso ontológico para as outras pessoas; ela é, portanto, e também, uma não referência. Em um mundo antinegro, a não pessoa negra é parte de um campo assimétrico de posicionalidades na medida em que a sua presença física é uma ameaça (e, portanto, sua ausência corporal uma necessidade), mas a sua ausência simbólica é inimaginável. Apesar de constituir a não presença, a não pessoa negra é fundamental para a constituição desse campo, o que quer dizer: a não pessoa negra é fundamental para a constituição das subjetividades modernas (FANON, 1967).

A fim de engajarmos plenamente com as implicações e consequências dessa perspectiva, é importante evitarmos uma tendência comum e compreensível: a procura de contraexemplos que reafirmam a Humanidade das pessoas negras. Sabemos de exemplos múltiplos, históricos e contemporâneos, da Humanidade radical negra, vital, Humanidade talvez única, de um mundo social distinto, que frequentemente opera de acordo com princípios éticos e estéticos não redutíveis à miséria existencial generalizada desse mundo (SHARPE, 2016). Talvez até, por tudo isso, uma Humanidade mais definida; ou, mesmo, uma outra Humanidade. Sabemos das formas de resistência, dos pensamentos transformativos, das metafísicas exploradoras, das artes inquietas e das ciências negras. Sabemos da tradição radical negra (NASCIMENTO, 1989; ROBINSON, 2000). Evitemos essas distrações e reconheçamos os princípios ontológicos e estruturais antinegros que organizam o mundo social da vida e da morte.

O que temos de entender, criticar e superar é o mundo presentemente constituído, o mundo da Humanidade que requer a não Humanidade da pessoa negra. Esse mundo constituído exige a degradação do Outro, um Outro paradigmaticamente negro. Um mundo, portanto, que é, ele mesmo, sinônimo de degradação. Um mundo em que os seus sujeitos, a fim de se firmarem enquanto sujeitos, têm de tornar objetos abjetos outros sujeitos, os sujeitos negros.

Para darmos conta da antinegritude, talvez seja útil pensarmos no seguinte esquema - imperfeito, decerto, mas que ilustra a singularidade da experiência negra vis-à-vis a outros grupos sociais oprimidos. Esse esquema tem por finalidade sugerir os desafios éticos distintos que grupos sociais oprimidos de maneiras singulares colocam ao mundo. Por que sofrem os trabalhadores? Por causa da exploração e da alienação a que estão sujeitos. Por que sofrem as mulheres? Por causa do patriarcado. Por que sofrem as pessoas lésbicas, gays, bissexuais e transexuais? Por causa do cis-heteropatriarcado. Por que sofrem as pessoas indígenas? Por causa do colonialismo, que quer sua terra. Por que sofrem as pessoas negras? Por causa da Humanidade. ${ }^{4}$ Note que todos os desafios éticos, com a exceção do último, são

\footnotetext{
${ }^{4}$ Esse esquema pode ser derivado dos textos de Wilderson (2010), como, por exemplo, Red, white, and black: cinema and the structure of U.S. antagonism.
} 


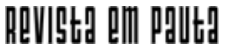

\} RACISMO NÃO DÁ CONTA - VARGAS, J. H. C. \}

DOI: $10.12957 /$ REP.2020.47201

potencialmente comensuráveis e cruzáveis. Por exemplo: a mulher trabalhadora indígena queer sofre por causa do capitalismo, do colonialismo e do cis-heteropatriarcado.

Estão anunciados, no que foi dito acima sobre a antinegritude, dois níveis de análise distintos: o primeiro nível examina os princípios ontológicos e estruturais que definem os termos das subjetividades modernas (acessíveis somente por meio de abstrações filosóficas e métodos que possibilitam captar traços do inconsciente) (EBERHARDT et al., 2004; GOFF et al., 2008); o segundo nível focaliza os processos subjetivos e sociais que se manifestam nas dinâmicas de sociabilidade (acessíveis por meio de métodos das ciências sociais). Apesar de os princípios ontológicos e os processos subjetivos e sociais estarem sempre e inevitavelmente ligados uns aos outros, eles ocorrem de modos distintos: uns através de dinâmicas cognitivas e culturais prescritivas, muitas vezes implícitas; outros, através de manifestações sociais, derivadas das dinâmicas prescritivas, que se atualizam de forma mais direta e pragmática.

Os processos sociais, assim, são, na melhor das hipóteses, uma tradução dos princípios ontológicos e de sociabilidade. Mas, como toda tradução, os processos sociais muitas vezes não expressam a essência, ou mesmo uma parcela da força simbólica, dos princípios sociais. É por isso que, em uma formação social como o Brasil, é ainda relativamente fácil apontar para "evidências" de que a antinegritude não existe ou foi ultrapassada. O conceito da democracia racial - e as pessoas e o aparato institucional que o sustentam - nada mais é do que a negação da antinegritude, negação esta fantasiada como uma celebração da ficção da inclusão multirracial.

Como o racismo, a antinegritude, portanto, existe mesmo quando não há manifestações explicitas de ódio às pessoas negras. Entretanto, ao contrário do racismo, a antinegritude não pode ser combatida por meio de decisões políticas e administrativas. A antinegritude, por não ser um desvio social, uma prática institucional, mas de fato uma constante estrutural, um código moderno de ontologia e sociabilidade que estrutura toda forma de interação humana, é imune a ajustes resultantes de políticas públicas e de esforços individuais.

Ao passo que o racismo é visto por aqueles que o combatem, ativistas e gestores de política públicas, por exemplo, como um fenômeno que pode ser remediado, a antinegritude não possibilita qualquer tipo de redenção. A não ser que haja uma reformulação completa de como nos entendemos e de como nos relacionamos. Como mudar o inconsciente coletivo, ou, mais especificamente, como modificar a noção de Humanidade, questões que dependem fundamentalmente da antinegritude? A antinegritude opera primordialmente, apesar de não exclusivamente, por meios implícitos, inconscientes.

Tais dinâmicas implícitas da antinegritude são ainda mais relevantes em contextos como os do Brasil e dos Estados Unidos, nos quais existe 


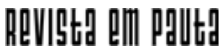

\} RACISMO NÃO DÁ CONTA - VARGAS, J. H. C. \}

DOI: $10.12957 /$ REP.2020.47201

um consenso de que o racismo é coisa superada, do passado. São, portanto, de importância ímpar as análises que apontam para a sobrevivência da antinegritude como um fato implícito - mas não menos efetivo -, mesmo quando o superego coletivo enfatiza uma multirracialidade mais ou menos harmônica. E com relação às formas implícitas e estruturais da antinegritude que as desvantagens que as pessoas negras vivenciam ganham justificativas cognitivas. A degradação das pessoas negras somente confirma o inconsciente coletivo que fundamentalmente desumaniza a pessoa negra (GORDON, 1999).

A antinegritude explica como um dado permanente do mundo moderno a aversão e o ódio às pessoas negras. Dentro do universo antinegro, a negritude é abjeta. "Essas pessoas negras não merecem tais recursos"; "essas pessoas negras não precisam de tantos recursos para sobreviver"; "essas pessoas negras têm mais tolerância à dor e portanto precisam de menos cuidados, medicamento, anestesia etc."; "essas pessoas negras são hipersexuais"; "essas pessoas negras são feias"; e "essas pessoas negras são predispostas à violência e ao crime, portanto têm de ser reprimidas": essas seriam algumas das manifestações sociais da lógica da antinegritude, a qual opera a partir de duas suposições cognitivas amplamente compartilhadas, apesar de raramente explicitadas: a primeira, que as não pessoas negras são indiscutivelmente sub ou não humanas; e a segunda, que essas não pessoas são parte inseparável (e mesmo indistinguível) de um universo social cuja moral, estética e ontologia são marcadamente distintos daquilo que define o mundo não negro.

A antinegritude torna abjeto tudo o que é supostamente ligado à negritude. A antinegritude torna não lugares todos os espaços marcados pela negritude: espaços físicos, espaços metafísicos, espaços ontológicos, espaços sociais. A antinegritude, portanto, define a não pessoa, o não lugar. Pense na associação imediata que é feita entre a palavra "favela" e negritude, ou "inner city" e negritude. As palavras, que denotam espaços sociais geograficamente delimitados, são imediatamente associadas à negritude, e assim os tornam lugares saturados de características negativas, poluidoras e ameaçadoras: não lugares. A pessoa negra não somente é desprovida de ontologia, mas é desprovida de lugar. Ela está sempre fora do lugar, seja lá qual for o lugar. Isso quer dizer que a antinegritude define também o lugar da pessoa moderna, da Humanidade, sempre presente e sempre localizada.

Ademais, a antinegritude é trans-histórica. Tempos históricos específicos codificam e condenam a negritude de maneiras particulares. A escravidão codifica o corpo negro como mercadoria; os direitos sociais codificam a pessoa negra como formalmente detentora de proteções, privilégios e obrigações. No entanto, há uma continuidade inegável: seja lá qual for o momento histórico e político, há sempre uma abundância de processos institucionais e sociais (como sugerem os estudos que se multiplicam sobre justiça penal e encarceramento) que consistentemente diminuem, tornam 


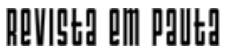

\} RACISMO NÃO DÁ CONTA - VARGAS, J. H. C. \}

DOI: $10.12957 /$ REP.2020.47201

ameaçadoras e matam pessoas negras gratuita e extralegalmente (FLAUZINA, 2008).

Seja lá qual for o momento histórico e político, e independentemente de proteções formais contra formas de discriminação, a não pessoa negra é aquela sobre a qual recai a violência gratuita (a violência que não tem motivo) e o estupro. Apesar de suas peculiaridades sociais e institucionais, as trajetórias do Brasil e dos Estados Unidos convergem na medida em que expressam formas de antinegritude consistentemente. Mais especificamente, podemos interpretar as manifestações históricas e contemporâneas da antinegritude, cujas formas mais óbvias são as violências perpetradas ou autorizadas pelo Estado - e apoiadas, mesmo que tacitamente, pela sociedade -, como o medo profundo da pessoa negra, da revolta negra: o medo fundamental de que a revolução do Haiti se repita fora do Haiti!

Finalmente, a antinegritude é a atmosfera que nos envolve, o ar que respiramos ${ }^{5}$. A antinegritude faz com que o nascimento da pessoa negra seja o início da morte social; a morte física prematura define sua não existência. Enquanto nos restringirmos a essa noção corrente de Humanidade, à qual correspondem normas sociais e arranjos institucionais, estaremos operando sob os efeitos da antinegritude. Trata-se de reinventar nossa Humanidade.

Termino esse ensaio breve oferecendo perguntas que talvez nos ajudem na busca de ferramentas teóricas e políticas na luta permanente e necessária contra a antinegritude. Se a presença negra é o problema fundamental de sociedades diaspóricas - problema de ordem ontológica, social e de administração política -, o que se pode esperar das estruturas de gerenciamento atuais (escolas, hospitais, polícia, cortes, Estado) a não ser a atualização da antinegritude? Se o que move as sociedades contemporâneas é o ódio às pessoas negras, quais as alternativas ideológicas e políticas a esse ódio? Pode esse ódio ser removido ou superado? Se o fantasma do Haiti - o medo profundo da insurreição negra, de uma sociedade negra para pessoas negras - organiza as sociabilidades e formas modernas de gerenciamento social, quais os modos de pensamento e as estratégias de organização e sobrevivência mais efetivos para comunidades negras que continuam sujeitas à lógica do genocídio antinegro?

Dado o momento de emergência pelo qual passam comunidades negras no Brasil e na diáspora, principalmente após a ascensão de governos cujas agendas são abertamente contra a sobrevivência social e física dessas comunidades, faz-se necessária a exploração de horizontes alternativos de análise e de atuação política. O momento é, de fato, incerto, mas não é

${ }^{5}$ Ver, para uma ideia semelhante, Christina Sharpe (2016), especialmente o capítulo no qual a autora argumenta sobre "o tempo" (the weather), usando como metáfora para discutir a antinegritude. A antinegritude, segundo ela, seria o tempo, ou o clima, numa tradução menos literal. Sneha. George, uma estudante de pós-graduação na Universidade da Califórnia, usou essa frase ("o ar que respiramos") num seminário durante o qual discutíamos o livro de Sharpe. 


\section{Revilgto am pallt}

\} RACISMO NÃO DÁ CONTA - VARGAS, J. H. C. \}

DOI: $10.12957 /$ REP.2020.47201

inédito. Mesmo durante os mandatos federais do Partido dos Trabalhadores, por mais que houvessem melhoras programáticas para pessoas negras nas áreas de renda, acesso a crédito, infraestrutura urbana, saúde e educação, desigualdades estruturais permaneceram. Entre as mais óbvias estão a diferença relativa de renda entre pessoas negras e não negras e os índices de mortes prematuras por causas evitáveis, incluindo doenças preveníveis ou tratáveis, e violência, sobretudo a provocada ou facilitada pelo Estado. Esses dois fatos, que sugerem não somente a exclusão social, mas também o pouco valor social da vida de pessoas negras, nos forçam a reconhecer a especificidade da condição das pessoas negras ${ }^{6}$. Por condição eu entendo a combinação de estruturas históricas e contemporâneas que definem os parâmetros das experiências individuais e coletivas de pessoas negras.

Mas há um potencial imenso de libertação quando aceitamos a antinegritude - o ódio fundamental contra as pessoas negras -, ao invés de tentarmos eliminá-la. Ao invés de tentarmos reformar as instituições, as pessoas, as normas e os costumes, podemos focalizar no que podemos fazer, ao contrário de tentarmos o que parece ser constitutivo, absoluto, imexível, impossível. O que pode acontecer quando pessoas negras aceitam esse ódio antinegro fundamental, um ódio global, e passam a desenvolver práxis que visam não à incorporação dentro de um mundo que não nos quer, mas à construção de um outro mundo? Uma outra Humanidade que não depende e deriva da antinegritude?

\footnotetext{
6 Ver, por exemplo, João Costa Vargas (2014), Black disidentification: the 2013 protests, rolezinhos and racial antagonism in Post-Lula Brazil; Osmundo Pinho e João Costa Vargas (2016), Antinegritude: o impossível sujeito negro da formação social brasileira; Ana Flauzina e João Costa Vargas (2017), Motim: os horizontes do genocídio antinegro na diáspora.
} 


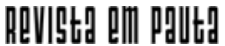

\} RACISMO NÃO DÁ CONTA - VARGAS, J. H. C. \}

DOI: $10.12957 /$ REP.2020.47201

\section{Referências}

COMBAHEE River Collective. The Combahee River Collective Statement, 1977. Disponível em: https://americanstudies.yale.edu/sites/default/files/files/ Keyword\%20Coalition_Readings.pdf. Acesso em: 20 nov. 2019.

EBERHARDT, J. et al. Seeing black: race, crime, and visual processing. Journal of Personality and Social Psychology, v. 6, n. 87, 2004.

FANON, F. Black skin, white masks. New York: Grove Press, 1967.

FLAUZINA, A. Corpo negro caído no chão: o sistema penal e o projeto genocida do Estado. Brasília: Contraponto, 2008.

FLAUZINA, A.; VARGAS, J. C. Motim: os horizontes do genocídio antinegro na diáspora. Editora Brado Negro, 2017.

GOFF, P. et al. Not yet human: implicit knowledge, historical dehumanization, and contemporary consequences. Journal of Personality and Social Psychology, v. 7, n. 94, 2008.

GORDON, L. R. Bad faith and antiblack racism. Amherst, NY: Humanity Books, 1999.

HARTMAN, S. Scenes of subjection: terror, slavery, and self-making in nineteenth-century America. New York: Oxford University Press, 1997.

JAMES, J. Shadowboxing: representations of black feminist politics. New York: Palgrave, 1999.

LIPSITZ, G. The Possessive Investment in Whiteness: how white people profit from identity politics. Philadelphia, PA: Temple University Press, 1998.

NASCIMENTO, A. do. Brazil, mixture or massacre? Essays on the genocide of a black people. Dover, MA: Majority Press, 1989.

OLIVEIRA, N. dos S. O caso do Estado e as questões raciais, origem e características sócio-econômicas de uma favela em Niterói, Estado do Rio de Janeiro. In: ROCHA, H. R.; CUNHA, M. E. Espaço urbano e afrodescendência: estudos da espacialidade negra urbana para o debate das políticas públicas. Fortaleza: Universidade Federal do Ceará Edições, 2007.

OLIVER, M.; SHAPIRO, T. Black wealth/white wealth: a new perspective on racial inequality. London: Routledge, 1995.

PINHO, O.; VARGAS, J. C. Antinegritude: o impossível sujeito negro da formação social brasileira. Bahia: Editora da UFRB, 2016.

ROBINSON, C. Black marxism: the making of the black radical tradition. Chapel Hill, NC: The University of North Carolina Press, 2000

SHARPE, C. In the wake: on blackness and being. Durham, NC: Duke University Press, 2016. 


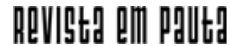

\} RACISMO NÃO DÁ CONTA - VARGAS, J. H. C. \}

DOI: $10.12957 /$ REP.2020.47201

VARGAS, J. C. Black disidentification: the 2013 protests, rolezinhos and racial antagonism in Post-Lula Brazil. Critical Sociology, 2014.

WILDERSON, F. B. Red, white and black: cinema and the structure of U. S. antagonism. Durham, NC: Duke University Press, 2010.

YANCEY, G. Who is white? Latinos, asians and the new black/nonblack divide. Boulder, CO: Lynne Rienner, 2004.

DOI: $10.12957 /$ rep.2020.47201

Recebido em 09 de setembro de 2019.

Aprovado para publicação em 15 de setembro de 2019.

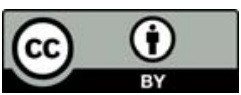

A Revista Em Pauta: Teoria Social e Realidade Contemporânea está licenciada com uma Licença Creative Commons Atribuição 4.0 Internacional. 